medRxiv preprint doi: https://doi.org/10.1101/2021.10.17.21264910; this version posted October 18, 2021. The copyright holder for this preprint (which was not certified by peer review) is the author/funder, who has granted medRxiv a license to display the preprint in perpetuity.

All rights reserved. No reuse allowed without permission.

\title{
Genetics of the human microglia regulome refines Alzheimer's disease risk loci
}

\section{Authors}

Roman Kosoy ${ }^{1,2,3,4 *}$, John F. Fullard ${ }^{1,2,3,4 *}$, Biao Zeng ${ }^{1,2,3,4 *}$, Jaroslav Bend1 $1^{1,2,3,4 *}$, Pengfei Dong ${ }^{1,2,3,4}$, Samir Rahman ${ }^{1,2,3,4}$, Steven P. Kleopoulos ${ }^{1,2,3,4}$, Zhiping Shao ${ }^{1,2,3,4}$, Jack Humphrey ${ }^{2,4,7,8}$, Katia de Paiva Lopes $^{2,4,7,8}$, Alexander W. Charney ${ }^{1,2,5}$, Brian. H. Kopel1 ${ }^{5,6,7,8}$, Towfique Raj ${ }^{2,4,7,8}$, David Bennett ${ }^{9,10}$, Christopher P. Kellner ${ }^{6}$, Vahram Haroutunian ${ }^{5,7,11}$, Gabriel E. Hoffman ${ }^{1,2,3} \dagger$, Panos Roussos ${ }^{1,2,3,4,5,11} \dagger^{* *}$

\section{Affiliations}

${ }^{1}$ Pamela Sklar Division of Psychiatric Genomics,

${ }^{2}$ Department of Genetics and Genomics Sciences, ${ }^{3}$ Icahn Institute for Data Science and Genomic Technology,

${ }^{4}$ Friedman Brain Institute,

${ }^{5}$ Department of Psychiatry,

${ }^{6}$ Department of Neurosurgery,

${ }^{7}$ Department of Neuroscience,

${ }^{8}$ Department of Neurology, Icahn School of Medicine at Mount Sinai, NY, USA

${ }^{9}$ Rush Alzheimer's Disease Center, Rush University Medical Center, Chicago, Illinois, USA

${ }^{10}$ Department of Neurological Sciences, Rush University Medical Center, Chicago, Illinois, USA

${ }^{11}$ Mental Illness Research Education, and Clinical Center (VISN 2 South), James J. Peters VA Medical Center, Bronx, NY, USA

*These first authors contributed equally to this work.

$\dagger$ These senior authors contributed equally to this work.

** Correspondence to: panagiotis.roussos@mssm.edu

\section{Abstract}

Microglia are brain resident myeloid cells that play a critical role in neuroimmunity and the etiology of Alzheimer's Disease (AD). Yet our understanding of how the genetic regulatory landscape controls microglial function and contributes to disease is limited. Here, we performed transcriptome and chromatin accessibility profiling in primary human microglia from 150 donors to identify geneticallydriven variation and cell-specific enhancer-promoter interactions. Integrative fine-mapping analysis identified putative regulatory mechanisms for $21 \mathrm{AD}$ risk loci, of which 18 were refined to a single gene, including 3 novel genes (KCNN4, FIBP and LRRC25). Transcription factor regulatory networks 
medRxiv preprint doi: https://doi.org/10.1101/2021.10.17.21264910; this version posted October 18, 2021. The copyright holder for this preprint (which was not certified by peer review) is the author/funder, who has granted medRxiv a license to display the preprint in perpetuity.

All rights reserved. No reuse allowed without permission.

captured AD risk variation and identified SPII as a key regulator of microglia expression and AD risk. This comprehensive resource capturing variation in the human microglia regulome provides novel insights into the etiology of neurodegenerative disease.

\section{One-Sentence Summary}

Characterizing the genetic regulation of chromatin accessibility and gene expression in human microglia refines molecular mechanisms of Alzheimer's disease risk loci.

Microglia are resident macrophage-like cells constituting $\sim 5-10 \%$ of all brain cells. Microglia display a diverse range of functions, mediated through interactions with neighboring glial and neuronal cells ${ }^{1}$. There is an increasing focus on understanding the molecular and genetic mechanisms involved in microglia function as they are central to multiple neurodegenerative disorders, including Alzheimer's disease (AD), Parkinson's disease (PD), multiple sclerosis (MS), and amyotrophic lateral sclerosis $(\mathrm{ALS})^{2,3}$. However, studying the regulatory and transcriptional mechanisms of human primary microglia is challenging as fresh brain material is not readily available.

Previous efforts have established the importance of microglia regulatory elements in the etiology of AD due to the enrichment of $\mathrm{AD}$ risk variants within regions of microglia specific accessible chromatin ${ }^{4-6}$. Expression quantitative trait loci (eQTL) datasets from primary microglia ${ }^{7,8}$ can help to map functional $\mathrm{AD}$ risk variants and nominate target genes. Genetic analysis of variation in chromatin accessibility will significantly enhance these efforts by identifying AD risk variants that directly affect transcriptional cis-regulatory activity, revealing the microglia-specific regulatory mechanisms disrupted in disease.

In the current study, we performed population-based analysis of the human microglia regulome and transcriptome to understand the role of transcription factor (TF) regulatory networks and the genetic regulatory landscape implicated in neurodegenerative diseases. We generated multi-omics data in microglia isolated from fresh human brain tissue of 150 unique donors and used this to develop an atlas of chromatin accessibility and to examine microglia-specific enhancer-promoter interactions. We then examined the population-level variation of gene expression and chromatin accessibility, and jointly utilized these resources to investigate the genetically driven regulation of transcription in microglia.

This approach enabled us to fine-map AD loci, identify novel putative AD risk genes and provide 
medRxiv preprint doi: https://doi.org/10.1101/2021.10.17.21264910; this version posted October 18, 2021. The copyright holder for this preprint (which was not certified by peer review) is the author/funder, who has granted medRxiv a license to display the preprint in perpetuity.

All rights reserved. No reuse allowed without permission.

mechanisms for how disease-associated risk variants contribute to the dysregulation of expression of microglia genes relevant to $\mathrm{AD}$.

\section{Landscape of chromatin accessibility and gene expression in primary human microglia}

We performed genotyping and generated ATAC-seq $(n=107)$, RNA-seq $(n=127)$ and Hi-C $(n=5)$ in primary human microglia isolated from fresh prefrontal cortex tissue from a total of 150 unique donors derived from biopsies $(n=27)$ and autopsies $(n=123)$ (Fig. 1a, Fig S1, Table S1, ). Microglia were isolated by fluorescent activated cell sorting (FACS) of viable $\mathrm{CD}^{+} 5^{+}$and $\mathrm{CD}_{11 \mathrm{~b}^{+}}$positive cells from dissociated brain specimens (Fig S2, see Methods). After data preprocessing, we retained 210,832 open chromatin regions (OCRs) (Fig. S3a) and 18,856 genes for further analyses, with 88 samples having high quality data for both ATAC-seq and RNA-seq (Fig S4). Our ATAC-seq (Fig. 1b) and RNA-seq (Fig. S5) data clustered closely with microglia from previous studies ${ }^{4,9,10}$ (Table S2).

We examined the overlap of our population-scale chromatin accessibility map with existing OCR datasets and genetic risk variants. Chromatin accessible regions from our data had higher overlap with microglia-specific OCRs (Jaccard $J=0.366$ ) relative to those from other brain cell populations (Jaccard $J$ between 0.138-0.178) ${ }^{6}$ (Fig. S3b). While observed enrichment was highest for promoters, distal OCRs showed the highest specificity for microglia and is consistent with higher cell type-specificity associated with distal regulation $\stackrel{11}{ }$. The relevance of microglia OCRs to human diseases was evaluated by examining enrichment for common genetic risk variants. Consistent with previous studies ${ }^{4,6,9,12}$, we observed an enrichment of AD risk variants $\frac{12}{2}$ specifically in microglia OCRs (Fig. 1c) (Table S3). Furthermore, microglial OCRs explained higher AD heritability (FoldChange $=4.0, p=0.013$, one-sided two-sample z-test) compared to OCRs discovered in broadly defined populations of non-neuronal cells ${ }^{5}$.

\section{Transcriptional regulation by open chromatin regions}

We next evaluated the coordination between the genome-wide OCR landscape and transcriptional activity in microglia using our unique resource of chromatin accessibility and gene expression data from the shared set of 88 donors. We fit a variance decomposition model for each gene to estimate the fraction of expression variation attributable to genome-wide variation in chromatin accessibility. Analysis of 185,664 OCRs, located within a $100 \mathrm{~kb}$ window centered around transcription start sites 
(TSS), revealed that variation in chromatin accessibility explained a median of $83.4 \%$ of expression variation across 18,640 genes, compared to a median of $0 \%$ explained in permuted data $\left(\mathrm{p}<10^{-323}\right.$, onesided Wilcoxon test) (Fig. 2a). Variation in chromatin accessibility explained at least $75 \%$ of transcriptional variance for $83.1 \%$ of the investigated genes $(15,491)$, indicating strong coupling between chromatin structure and gene expression in human microglia (Fig. S6).

Next, with the aim of linking a regulatory element to the gene(s) it regulates, we used a recently developed "activity-by-contact" (ABC) framework ${ }^{13}$ to combine our Hi-C derived contact frequencies with "enhancer activities" in OCRs to examine long-range enhancer-promoter (E-P) interactions (Fig. 2b). We identified 24,497 E-P interactions, involving 9,890 unique genes, thus identifying at least one non-promoter regulatory element for over $52 \%$ of microglia expressed genes. About half of the E-P linked OCRs, termed $\mathrm{OCR}_{\mathrm{ABC}}$, were linked to more than one gene, and over $60 \%$ of the linked genes were linked to multiple $\mathrm{OCR}_{\mathrm{ABC}}$ (Fig. 2b). As demonstrated previously (15), OCR $\mathrm{OBC}_{\mathrm{ABC}}$ more often did not target the nearest gene (72\% OCR $\mathrm{ABC}_{\mathrm{BC}}$ skipped at least one gene) (Fig. 2b), further highlighting the importance of experimentally derived regulatory annotations.

$\mathrm{OCR}_{\mathrm{ABC}}$ have a significantly higher correlation with the expression of linked genes compared to unlinked genes $\left(\mathrm{p}<10^{-95}\right.$, one-sided Wilcoxon test) (Fig. 2c, as well as to chromatin accessibility at the linked promoter compared to OCRs that do not participate in E-P interactions $\left(\mathrm{p}<10^{-323}\right.$, one-sided Wilcoxon test) (Fig. 2d). As expected ${ }^{13}$, the majority of observed E-P interactions corresponded to a positive correlation between gene expression and chromatin accessibility (Fig. S7a-b). To evaluate the cell type specificity of the E-P interactions observed in microglia, we compared them to E-P pairs identified in broad neuronal (38,233 pairs) and non-neuronal (37,056 pairs) cell populations ${ }^{14}$. In total, $23.6 \%(5,781$ out of 24,459$)$ microglia E-P interactions were shared with either neurons or non-neurons (Fig. S8a-b). As expected, we observed a stronger overlap between microglial and non-neuronal $(\mathrm{OR}=13.7)$ E-P interactions than with those of neurons $(\mathrm{OR}=7.5)$ (Fig. 2e; Fig. S8c). Conversely, over $76 \%$ of the E-P interactions were observed in microglia alone, reflecting the cell-type specificity of regulatory mechanisms.

To further explore the importance of cell type-specific regulatory mechanisms and their role in disease, we quantified the overlap of disease risk variants with $\mathrm{OCR}_{\mathrm{ABC}}$ from neurons, glia, and microglia. Similar to analysis of all OCRs above (Fig. 1f), enrichment of AD risk variants was only observed in microglia $\mathrm{OCR}_{\mathrm{ABC}}$ (Fig. 2f). Strikingly, limiting analysis to microglial E-P interactions increases the 
medRxiv preprint doi: https://doi.org/10.1101/2021.10.17.21264910; this version posted October 18, 2021. The copyright holder for this preprint (which was not certified by peer review) is the author/funder, who has granted medRxiv a license to display the preprint in perpetuity.

All rights reserved. No reuse allowed without permission.

explained heritability coefficient for $\mathrm{AD}$ (fold change $=7.2, \mathrm{p}=0.0016$, one-sided two-sample $\mathrm{z}$-test). This highlights the central role for transcriptional regulatory mechanisms of human microglia in the genetic architecture of AD.

\section{Genetic regulation of chromatin accessibility in human microglia}

ATAC-seq and high-density genotyping data from 95 donors allowed us to study population variation by generating a human microglia chromatin accessibility QTL (caQTL) map. Utilizing the multivariate multiple QTL (mmQTL) method ${ }^{15}$, and correcting for multiple technical confounds (Fig. S9) and population structure, we used a $50 \mathrm{~kb}$ window centered on each of 210,832 OCRs and identified 5,468 OCRs with significant caQTLs. Our microglia caQTL dataset had high concordance with caQTLs identified in human iPSC-derived macrophages, derived under various stimulating conditions (range of $\pi 1$ values: 0.662 to 0.753 ), reflecting the shared myeloid origin of microglia and macrophages ${ }^{16}$ (Fig. S10a). The replication of microglia caQTLs was lower in caQTLs derived from homogenate brain specimens $\left(\pi_{1}=0.602\right)^{17}$.

Given the high concordance of caQTLs among microglia and myeloid cells, we maximized statistical power for caQTL detection by jointly analyzing our human microglia and four macrophage datasets ${ }^{16}$. The resulting human microglia meta-caQTL dataset contained 10,266 OCRs with significant caQTLs. Bayesian analysis of results from these two cell types indicate that the majority of caQTLs were either discovered in microglia alone or had comparable level of support from the macrophage subsets ${ }^{18}$ (Fig. 3a). By applying a fine-mapping approach ${ }^{19}$ to the meta-caQTL results, we identified a $95 \%$ credible set of 269,536 SNPs, including 144,592 SNPs (called caSNPs) with posterior probability (PP) $>0.01$ for 10,152 OCRs (Fig. S11a). Of these, 6,476 caSNPs were located within 4,324 OCR peaks (Fig. S12a-b).

Since genetic regulatory architecture varies across tissues and cell types ${ }^{20}$, we evaluated the cell type specificity of the fine-mapped caSNPs with PP $>0.01$ and, within OCRs, by querying the predicted effect of each variant on 2,002 epigenetic assays across tissues and cell lines from ENCODE and the Roadmap Epigenomics Project estimated by DeepSEA ${ }^{21,22}$. Even without considering any prior knowledge about the cell type of origin, the epigenetic tracks predicted to be most disrupted by this set of caSNPs were DNAse hypersensitivity sites (DHS) from primary $\mathrm{CD}^{+} 4^{+}$monocytes (Fig. 3b). Assayed epigenetic tracks in other myeloid lineage cell types were also disrupted. Moreover, the 
medRxiv preprint doi: https://doi.org/10.1101/2021.10.17.21264910; this version posted October 18, 2021. The copyright holder for this preprint (which was not certified by peer review) is the author/funder, who has granted medRxiv a license to display the preprint in perpetuity.

All rights reserved. No reuse allowed without permission.

direction of the predicted effect was consistent with the known biology of these assays. For example, caQTL and DeepSEA effect directions were positively correlated with changes in DHS and ChIP-seq marks indicative of promoter and enhancer activity from myeloid lineages, and negatively correlated with changes in repressive epigenetic marks (Fig. 3c).

We evaluated the degree to which genetic variants affecting chromatin accessibility acted by disrupting transcription factor binding sites (TFBS). We employed a TF footprinting approach ${ }^{23}$ to identify all bound TFs within the microglia accessible chromatin landscape. caSNPs were more likely to be located within occupied TFBSs, as determined by footprinting analysis $\left(\mathrm{OR}=1.10, \mathrm{p}=6.95 \times 10^{-5}\right.$, Fisher's exact test). We identified 53 TFs whose predicted binding was significantly enriched for dysregulation by caSNPs, as compared to non-caSNP genetic variants present within OCRs (Table S4). Among these, predicted SPI1 binding sites were the most significantly disrupted by caSNPs (OR=5.56, $\mathrm{FDR}=5.65 \times 10^{-55}$, Fisher's exact test) and the effect direction from caQTL analysis was concordant with the predicted TFBS disrupting allele at $92 \%$ of caSNPs $\left(\mathrm{p}=6.6 \times 10^{-4}\right.$, binomial test) (Fig. S13). While increasing the fine-mapping posterior probability cutoff for caSNPs increased the concordance for all TFs, predicted SPII binding sites remained remarkably concordant across a wide range of cutoffs (Fig. 3d). The SPII gene encodes PU.1, which is a master regulator of myeloid cell development and critical for microglia function ${ }^{24}$. Our observation reinforces the importance of genetic regulation of PU.1 target genes in human primary microglia.

\section{Coordinated genetic regulation of chromatin accessibility and gene expression}

Using the same approach as for caQTLs, eQTL analysis on samples from 101 donors identified 1,603 eQTLs at 5\% FDR (Fig. S9b). These microglia eQTLs were replicated in two other human microglia eQTL datasets (range of $\pi_{1}: 0.62$ to 0.70$)^{8,25}$ (Fig. S10b). Given the high concordance, we performed meta-analysis and statistical fine-mapping of these 3 datasets, and identified 7,302 meta-eQTLs (Fig. S9b; Fig. S12c). Fine-mapped eSNPs were overrepresented within $\mathrm{OCR}_{\mathrm{ABC}}$ corresponding to their target genes $(\mathrm{OR}=1.48$, permutation test $\mathrm{p}=6.7 \mathrm{x} 10-5)($ Fig. $\mathbf{S 1 4})$.

Having shown that eSNPs are more likely to colocalize with E-P interaction, we next sought to examine the genetically driven regulation of transcription in microglia. Fine-mapped caSNPs within $\mathrm{OCR}_{\mathrm{ABC}}$ regions were more likely to be fine-mapped eSNPs for the target gene compared to caSNPs for OCRs not involved in E-P interactions (Fig. 3e). Genetic colocalization analysis ${ }^{26}$ identified 1,457 
medRxiv preprint doi: https://doi.org/10.1101/2021.10.17.21264910; this version posted October 18, 2021. The copyright holder for this preprint (which was not certified by peer review) is the author/funder, who has granted medRxiv a license to display the preprint in perpetuity.

All rights reserved. No reuse allowed without permission.

instances where pairs of gene expression and chromatin accessibility traits shared genetic regulatory architecture with high posterior probability (i.e. PP4>0.5, including 865 unique genes and 1,033 unique OCRs (Fig. S15a). Of these, 167 OCR-gene pairs were also E-P links identified via ABC (Fig. S15c). OCRs predicted to be involved in E-P interactions were enriched for being colocalized with an eQTL for the target gene $\left(\mathrm{OR}=2.5\right.$, permutation test $\left.\mathrm{p}=6.7 \times 10^{-5}\right)$ (Fig. S15d).

Taken together, we have captured variation of the regulatory mechanisms that are involved in microglia E-P interactions which we further integrated with risk loci across multiple traits. We evaluated the overlap of microglia regulatory variants in the $95 \%$ credible sets for gene expression and chromatin accessibility with risk variants for common diseases. While eSNPs showed significant enrichment for a range of neurodegenerative, inflammatory and neuropsychiatric traits (15 of 20 tested), caSNPs showed a more specific signal with three traits, including the largest heritability coefficient for AD (Fig. 3f). Integrating fine-mapping for chromatin accessibility and gene expression (see Methods) produced a refined set of 30,028 variants showing significant enrichment for AD risk loci ( $p=0.036)$ (Fig. S16), pointing to a key role for the genetic regulation of gene expression via chromatin accessibility in AD.

\section{Integration of microglia regulome with AD risk variation}

Having shown the high specificity of the microglia regulome for $\mathrm{AD}$ genetic risk architecture, we performed fine-mapping to better identify AD credible causal variants, genes and regulatory regions. We first examined the colocalization of fine-mapped AD risk variants ${ }^{12}$ within microglia E-P interactions. Remarkably, 6,428 distal $\mathrm{OCR}_{\mathrm{ABC}}(>20 \mathrm{~kb}$ from the nearest TSS) contained 20 fine-mapped SNPs (PP>0.01) from eight different AD loci, while the 97,513 of the equidistant OCRs with low ABC scores contained none of the fine-mapped SNPs $\left(\mathrm{OR}=318, \mathrm{p}=8.9 \times 10^{-25}\right.$, Fisher's exact text) (Fig. 4a; Table S5).

We then combined AD genetic risk variation ${ }^{12}$ with the microglia meta-eQTL and meta-caQTL datasets using multiple-trait-coloc (moloc) ${ }^{27}$ to link AD loci to genes and regulatory regions (Table S6). We observed GWAS-eQTL-caQTL colocalization within six previously reported AD loci (Fig. 4b), providing coherent units of transcriptional regulation relevant to the etiology of $\mathrm{AD}$. Colocalization analyses between the AD GWAS and meta-eQTL and meta-caQTLs, separately, provided functional annotation for five additional published $\mathrm{AD}$ loci. Importantly, the integration of allele specific information from eQTL and AD GWAS allowed us to unambiguously define the direction of the transcriptional changes in relation to increased $\mathrm{AD}$ risk for the fine-mapped genes (Fig. $\mathbf{4 b}$, rightmost 
medRxiv preprint doi: https://doi.org/10.1101/2021.10.17.21264910; this version posted October 18, 2021. The copyright holder for this preprint (which was not certified by peer review) is the author/funder, who has granted medRxiv a license to display the preprint in perpetuity.

All rights reserved. No reuse allowed without permission.

column). PICALM is a previously well-supported disease gene ${ }^{28}$, where we found that the AD risk variant (rs10792832) was within an $\mathrm{OCR}_{\mathrm{ABC}}$, and the risk allele was associated with both lower OCR signal and gene expression, which is consistent with predicted (DeepSEA) reduced DNase accessibility and H3K4me1 ChIP-seq signal in monocytes (Fig. 4c, 4d).

For three $\mathrm{AD}$ loci, moloc analyses provided support for involvement of only one among the multiple previously suggested risk associated genes at each locus: EPHA1-AS1, USP6NL, and CCDC6. The EPHA1-AS1 locus is of particular interest as our analysis prioritized it over the EPHA1 protein coding gene, and its 95\% credible set contains a single SNP (Fig. S17, Fig. S18). EPHA1-AS1 is a lncRNA gene with a previously undefined function, which we predicted to participate in immune-related pathways based on functional annotations of the co-regulated genes (Fig. S19).

Intriguingly, we identified three instances of colocalization between AD GWAS and microglia metaeQTL at genetic regions not previously highlighted as AD loci, for genes FIBP, LRRC25 and KCNN4, with the moloc colocalization with meta-caQTLs also observed for the latter (Fig. 4b; Table S6, Fig. S20; Fig. S21; Fig. S22). The known biology of all three genes is highly compatible with AD pathophysiology, with KCNN4 having been previously considered as an AD therapeutic target ${ }^{29}$. Importantly, the utilization of the generated microglia-specific regulome resources allowed us to identify AD relevant coherent regulatory units for 18 out of $21 \mathrm{AD}$ loci for which were able to observe fine-mapping evidence, highlighting the importance of obtaining data from the relevant cell type.

\section{Transcription factor regulatory networks capture AD genetic variation}

TFs are involved in the precise tuning of microglial homeostasis and are implicated in AD pathogenesis $^{30,31}$. In parallel to pursuing the colocalization approaches and E-P annotation to link AD risk loci to genes, we also utilized chromatin accessibility to establish the TF activity in microglia and to query the identified TF targets for AD risk variant enrichment. We performed TF footprinting analysis ${ }^{23}$ in microglia, as well as oligodendrocytes and GABAergic and glutamatergic neurons ${ }^{5}$ for comparative analysis. PU.1 (encoded by SPI1), IRF6, STAT2, and NFKB2 were identified as microglia-specific TFs (Fig. 5a; Table S7), reflecting known microglial immune-related processes ${ }^{24,32-}$ ${ }^{34}$, with PU.1 identified as the strongest microglia-specific TF ${ }^{35}$ (Fig. 5c). Among the 26,003 OCRs with predicted PU.1 binding, 86\% (OR=16.2, $\mathrm{p}<10-16$, Fisher's exact test) matched sites identified by PU.1 ChIP-seq ${ }^{9}$, further validating the in silico footprinting approach to detect microglial TFs. 
medRxiv preprint doi: https://doi.org/10.1101/2021.10.17.21264910; this version posted October 18, 2021. The copyright holder for this preprint (which was not certified by peer review) is the author/funder, who has granted medRxiv a license to display the preprint in perpetuity.

All rights reserved. No reuse allowed without permission.

Cross-regulation among groups of TFs in a given cell type defines regulatory subnetworks that underlie cellular identity and facilitate the integration of complex cellular signals. Using predicted TF binding within OCRs from footprinting analysis, we constructed a directed TF-to-TF regulatory network (TFRN) capturing the hierarchical TF regulome in microglia (Fig. 5c, Fig. S23). We then used AD genetic risk variants ${ }^{12}$ to assign weights to the nodes in the generated TFRN ${ }^{36}$ and identified subnetworks composed of 11 TF motifs jointly representing perturbed regulatory hubs in AD (Fig. 5d). Of the $23 \mathrm{TF}$ genes corresponding to these motifs, 16 were expressed in microglia.

We prioritized TFs within this set based on the correlation of TF gene expression with the expression of their respective predicted target genes. Expression of PU.1-encoding SPII had the strongest correlation with the transcriptional landscape of its 4,226 predicted target genes (Fig. 5e, Fig. S24). Altogether, we observed significant downstream signatures for 10 of the $16 \mathrm{TF}$ genes (Fig. 5e, left column). Reflecting known microglial biology, the downstream target genes for three of these TFs (SPII/PU.1, IRF1 and ZNF143) have a predominantly immune function as illustrated by the over-representation of immune related signatures among the enriched biological pathways (Fig. 5e, right column).

\section{Discussion}

In the current study, we examined how genetic regulation of chromatin accessibility affects transcription in primary human microglia. With microglia comprising a small fraction of all brain cells, any resources generated using brain homogenate do not comprehensively capture the microglia-specific regulome. To address this gap in our knowledge, we generated multi-omics data comprising ATAC-seq, RNA-seq, and Hi-C using microglia cells isolated from 150 unique donors. We present the largest, microglia specific, meta-eQTL analysis to date and the first publicly available human microglia caQTL dataset. Incorporating Hi-C derived 3D chromosomal loop data allowed us to link accessible chromatin to target genes, leading to the identification of $\sim 25,000$ discrete regulatory E-P units, regulating 9,890 genes. The majority of these interactions were not observed in analysis of previous data sets.

In 14 previously implicated $\mathrm{AD}$ risk loci, we identified disease regulatory units associated with expression of an individual gene. We confirmed previously implicated genes, BIN1, PICALM, CD33, CASS4, ADAMTS4, INPP5D and APH1B, in 7 independent loci ${ }^{37,38}$. Going one step further, our approach allowed us to fine-map AD risk loci and identified 8 genes, EPHA1-AS1, USP6NL, CCDC6, 
medRxiv preprint doi: https://doi.org/10.1101/2021.10.17.21264910; this version posted October 18, 2021. The copyright holder for this preprint (which was not certified by peer review) is the author/funder, who has granted medRxiv a license to display the preprint in perpetuity.

All rights reserved. No reuse allowed without permission.

$A C 099524.1, Z N F 652, M S 4 A 4 E, R A B E P 1$ and $C L U$, as the causal genes in previously unresolved loci containing multiple candidate $\mathrm{AD}$ risk genes.

In the case of EPHA1-AS1, this locus is an example where our multi-omics approach enabled finemapping of a particular $\mathrm{AD}$ risk gene paired with the genetic regulatory mechanisms affecting its expression. Here, a genetic variant, rs11771145, comprises the 95\% confidence intervals for EPHA1ASI and two OCRs (peak 188003 at 143,413,799-143,414,777 and peak 188007 at 143,458,143$143,458,744$, on chromosome 7) located $6 \mathrm{~kb}$ and $51 \mathrm{~kb}$ from the gene's TSS, respectively. Rs 11771145 is located $130 \mathrm{bp}$ from the peak 188003, with ATAC-seq signal at the OCR strongly $(\mathrm{r}=0.69)$ correlated with the expression of EPHA1-AS1. This SNP has the strongest association with AD at the locus in the original International Genomics of Alzheimer's Project (I-GAP) study ${ }^{39}$ and in the most recent European Alzheimer's Disease BioBank (EADB) study ${ }^{38}$. Interestingly, though rs11771145 was not included within the $95 \%$ credible interval in the AD GWAS ${ }^{12}$ utilized in the colocalization analyses presented here, we still observed significant evidence linking the genetic regulation of EPHA1-AS1 with $\mathrm{AD}$ etiology through the regulation of at least one regulatory element.

Importantly, while the majority of the observed colocalization were seen within previously reported AD loci, our colocalization analyses also identified three novel putative AD risk genes, namely $K C N N 4$, FIBP and LRRC25. LRRC25 regulates virally induced autophagy in myeloid cells ${ }^{38}$. FIBP binds to acidic fibroblast growth factor (aFGF), which is released by astrocytes and enhances the activation of human microglia following LPS/IFN- $\gamma$ stimulation ${ }^{41}$. Therefore, FIBP may be an intriguing link in the astrocyte-microglia axis of AD. KCNN4, on the other hand, has been extensively pursued as a therapeutic AD target due to its role in the removal of neurotoxic debris by phagocytosis ${ }^{29}$. Our analysis indicates that alleles associated with decreased expression of all three of these genes are associated with increased AD risk.

By applying TF footprinting analysis we were able to identify TF regulatory networks. TFs whose regulatory neighborhood is enriched in AD risk genes were prioritized and, of those, the TF with the strongest downstream effect was PU.1 (encoded by SPI1). SPI1 has previously been associated with increased $\mathrm{AD}$ risk ${ }^{24,42}$. CaSNPs were disproportionately overrepresented within PU.1 binding sites and, in $92 \%$ of these, alleles associated with lower OCR strength disrupt PU.1 binding motifs. A similar, albeit weaker, effect was observed for eSNPs. Thus, genetic variants that decrease binding of PU.1 were sufficient to interfere with the stability of chromatin accessibility. This observation, combined 
medRxiv preprint doi: https://doi.org/10.1101/2021.10.17.21264910; this version posted October 18, 2021. The copyright holder for this preprint (which was not certified by peer review) is the author/funder, who has granted medRxiv a license to display the preprint in perpetuity.

All rights reserved. No reuse allowed without permission.

with the transcriptional changes associated with SPI1 expression, highlight a regulatory role for SPI1/PU.1 in microglia, with particular relevance to AD. We replicate previous evidence supporting PU.1 as a transcriptional factor critical to microglial contribution to $\mathrm{AD}{ }^{24,35,42}$, and further identify additional TFs implicated in AD.

Altogether, our multi-omic data set provides unprecedented insight into the regulation of microglia transcription, enabling annotation of a large number of distal regulatory elements and downstream genes. The strong enrichment of AD risk variants in microglia OCRs further establish microglia as a cell-type central to AD development. We were able to fine-map multiple AD loci, identifying not only the relevant genes but, in some cases, proposing the regulatory mechanisms contributing to disease, thus allowing further exploration of the nuances of genetic landscape contributing to particular neurodegenerative phenotypes. In conclusion, this resource provides an atlas of the human microglia regulome that can be leveraged by the scientific community to guide focused experiments in $\mathrm{AD}$ and other neurodegenerative diseases and to understand the impact on transcription of a particular risk locus.

\section{Materials and methods summary}

The ATAC-seq $(n=107)$, RNA-seq $(n=127)$, SNP array $(n=122)$, and Hi-C $(n=5)$ data were generated from human brains of 150 individuals from four biobank resources (three based in New York City, NY, and ROSMAP from Rush University, Chicago, IL), including 123 autopsies and 27 biopsies. Brain tissue dissections from cortical regions were processed and subjected to FACS to isolate viable CD45+ microglia. ATAC-seq libraries were generated using an established protocol and processed through our bioinformatics pipeline $^{5}$, with 210,832 OCRs called via MACS2 ${ }^{43}$. We applied variance component analysis to quantify the proportion of gene expression variation attributable to OCR covariance. To predict enhancer-promoter interactions, we employed the "activity-by-contact" method that is based on the combination of frequency (derived from $\mathrm{Hi}-\mathrm{C}$ ) and enhancer activity (derived from microglia ATAC-seq and H3K27ac ChIP-seq). We identified 24,497 E-P interactions. Transcription factors involved in the regulation of gene expression were identified by footprinting analysis in TOBIAS and modeled as a regulatory network. We then applied HotNet to find altered subnetworks containing TF motifs that are highly dysregulated between $\mathrm{AD}$ cases and controls based on transcriptomics and 
327 GWAS weights. We utilized the mmQTL method to identify 5,468 caQTLs in 95 samples, and 1,603

328 eQTLs in 101 samples. Meta-analysis utilizing summary statistics from two recently generated human

329 microglia eQTL datasets allowed us to identify 7,302 meta-eQTLs with an effective sample size of 400.

330 Similarly, 10,266 meta-caQTL were identified by integrating caQTLs from human macrophages

331 (effective size =216). Functional impact of the identified caSNPs was evaluated via their effect on

332 epigenetic states across multiple cell types in DeepSEA, as well as predicting changes to motif binding

333 affinity in motifbreakR. To identify genes and accessible chromatin regions that share genetic

334 regulation, colocalization analysis was performed with the coloc method, resulting in 1,457 co-

335 regulated Gene-OCR pairs. Coloc was also utilized to detect colocalization between neurodegenerative

336 disease predisposing genetic variants and meta-eQTLs or meta-caQTLs. Coherent units of genes and

337 regulating OCRs relevant to $\mathrm{AD}$ risk were identified via multiple-trait-coloc (moloc). The detailed

338 Materials and Methods are described in the Supplementary Materials. 
medRxiv preprint doi: https://doi.org/10.1101/2021.10.17.21264910; this version posted October 18, 2021. The copyright holder for this preprint (which was not certified by peer review) is the author/funder, who has granted medRxiv a license to display the preprint in perpetuity.

All rights reserved. No reuse allowed without permission.

339

340

341

342

343

344

345

346

347

348

349

350

351

352

353

354

355

356

357

\section{Bibliography}

1. Salter, M. W. \& Stevens, B. Microglia emerge as central players in brain disease. Nat. Med. 23,

1018-1027 (2017).

2. Bartels, T., De Schepper, S. \& Hong, S. Microglia modulate neurodegeneration in Alzheimer's and

Parkinson's diseases. Science 370, 66-69 (2020).

3. Song, W. M. \& Colonna, M. The identity and function of microglia in neurodegeneration. Nat.

Immunol. 19, 1048-1058 (2018).

4. Nott, A. et al. Brain cell type-specific enhancer-promoter interactome maps and disease-risk association. Science 366, 1134-1139 (2019).

5. Hauberg, M. E. et al. Common schizophrenia risk variants are enriched in open chromatin regions of human glutamatergic neurons. Nat. Commun. 11, 5581 (2020).

6. Corces, M. R. et al. Single-cell epigenomic analyses implicate candidate causal variants at inherited risk loci for Alzheimer's and Parkinson's diseases. Nat. Genet. 52, 1158-1168 (2020).

7. Young, A. M. H. et al. A map of transcriptional heterogeneity and regulatory variation in human microglia. Nat. Genet. 53, 861-868 (2021).

8. de Paiva Lopes, K. et al. Atlas of genetic effects in human microglia transcriptome across brain regions, aging and disease pathologies. BioRxiv (2020) doi:10.1101/2020.10.27.356113.

9. Gosselin, D. et al. An environment-dependent transcriptional network specifies human microglia identity. Science 356, (2017). 
medRxiv preprint doi: https://doi.org/10.1101/2021.10.17.21264910; this version posted October 18, 2021. The copyright holder for this preprint (which was not certified by peer review) is the author/funder, who has granted medRxiv a license to display the preprint in perpetuity.

All rights reserved. No reuse allowed without permission.

358

359

360

361

362

363

364

365

366

367

368

369

370

371

372

373

374

375

376

10. Novikova, G. et al. Integration of Alzheimer's disease genetics and myeloid genomics identifies

disease risk regulatory elements and genes. Nat. Commun. 12, 1610 (2021).

11. Liu, X. et al. Functional architectures of local and distal regulation of gene expression in multiple human tissues. Am. J. Hum. Genet. 100, 605-616 (2017).

12. Jansen, I. E. et al. Genome-wide meta-analysis identifies new loci and functional pathways influencing Alzheimer's disease risk. Nat. Genet. 51, 404-413 (2019).

13. Fulco, C. P. et al. Activity-by-contact model of enhancer-promoter regulation from thousands of CRISPR perturbations. Nat. Genet. 51, 1664-1669 (2019).

14. Bendl, J. et al. The three-dimensional landscape of chromatin accessibility in Alzheimer's disease. BioRxiv (2021).

15. Zeng, B. et al. Trans-ethnic eQTL meta-analysis of human brain reveals regulatory architecture and candidate causal variants for brain-related traits. medRxiv (2021) doi:10.1101/2021.01.25.21250099.

16. Alasoo, K. et al. Shared genetic effects on chromatin and gene expression indicate a role for enhancer priming in immune response. Nat. Genet. 50, 424-431 (2018).

17. Bryois, J. et al. Evaluation of chromatin accessibility in prefrontal cortex of individuals with schizophrenia. Nat. Commun. 9, 3121 (2018).

18. Han, B. \& Eskin, E. Interpreting meta-analyses of genome-wide association studies. PLoS Genet. 8, e1002555 (2012) 
medRxiv preprint doi: https://doi.org/10.1101/2021.10.17.21264910; this version posted October 18, 2021. The copyright holder for this preprint (which was not certified by peer review) is the author/funder, who has granted medRxiv a license to display the preprint in perpetuity.

All rights reserved. No reuse allowed without permission.

377

378

379

380

381

382

383

384

385

386

387

388

389

390

391

392

393

394

19. Hormozdiari, F., Kostem, E., Kang, E. Y., Pasaniuc, B. \& Eskin, E. Identifying causal variants at loci with multiple signals of association. Genetics 198, 497-508 (2014).

20. Kim-Hellmuth, S. et al. Cell type-specific genetic regulation of gene expression across human tissues. Science 369, (2020).

21. Zhou, J. \& Troyanskaya, O. G. Predicting effects of noncoding variants with deep learning-based sequence model. Nat. Methods 12, 931-934 (2015).

22. Zhou, J. et al. Deep learning sequence-based ab initio prediction of variant effects on expression and disease risk. Nat. Genet. 50, 1171-1179 (2018).

23. Bentsen, M. et al. ATAC-seq footprinting unravels kinetics of transcription factor binding during zygotic genome activation. Nat. Commun. 11, 4267 (2020).

24. Huang, K.-L. et al. A common haplotype lowers PU.1 expression in myeloid cells and delays onset of Alzheimer's disease. Nat. Neurosci. 20, 1052-1061 (2017).

25. Young, A. et al. A map of transcriptional heterogeneity and regulatory variation in human microglia. BioRxiv (2019) doi:10.1101/2019.12.20.874099.

26. Giambartolomei, C. et al. Bayesian test for colocalisation between pairs of genetic association studies using summary statistics. PLoS Genet. 10, e1004383 (2014).

27. Giambartolomei, C. et al. A Bayesian framework for multiple trait colocalization from summary association statistics. Bioinformatics 34, 2538-2545 (2018). 
medRxiv preprint doi: https://doi.org/10.1101/2021.10.17.21264910; this version posted October 18, 2021. The copyright holder for this preprint (which was not certified by peer review) is the author/funder, who has granted medRxiv a license to display the preprint in perpetuity.

All rights reserved. No reuse allowed without permission.

395

396

397

398

399

400

401

402

403

404

405

406

407

408

409

410

411

412

413

28. Xiao, Q. et al. Role of phosphatidylinositol clathrin assembly lymphoid-myeloid leukemia

(PICALM) in intracellular amyloid precursor protein (APP) processing and amyloid plaque

pathogenesis. J. Biol. Chem. 287, 21279-21289 (2012).

29. Kaushal, V., Koeberle, P. D., Wang, Y. \& Schlichter, L. C. The Ca2+-activated K+ channel

$\mathrm{KCNN} 4 / \mathrm{KCa} 3.1$ contributes to microglia activation and nitric oxide-dependent neurodegeneration.

$$
\text { J. Neurosci. 27, 234-244 (2007). }
$$

30. Rahman, M. R. et al. Network-based approach to identify molecular signatures and therapeutic agents in Alzheimer's disease. Comput. Biol. Chem. 78, 431-439 (2019).

31. Acquaah-Mensah, G. K. \& Taylor, R. C. Brain in situ hybridization maps as a source for reverseengineering transcriptional regulatory networks: Alzheimer's disease insights. Gene 586, 77-86 (2016).

32. Xu, J. et al. IL-4/STAT6 signaling facilitates innate hematoma resolution and neurological recovery after hemorrhagic stroke in mice. Proc Natl Acad Sci USA 117, 32679-32690 (2020).

33. Frakes, A. E. et al. Microglia induce motor neuron death via the classical NF- $\kappa$ B pathway in amyotrophic lateral sclerosis. Neuron 81, 1009-1023 (2014).

34. Lavin, Y. et al. Tissue-resident macrophage enhancer landscapes are shaped by the local microenvironment. Cell 159, 1312-1326 (2014).

35. Morabito, S. et al. Single-nucleus chromatin accessibility and transcriptomic characterization of Alzheimer's disease. Nat. Genet. 53, 1143-1155 (2021). 
medRxiv preprint doi: https://doi.org/10.1101/2021.10.17.21264910; this version posted October 18, 2021. The copyright holder for this preprint (which was not certified by peer review) is the author/funder, who has granted medRxiv a license to display the preprint in perpetuity.

All rights reserved. No reuse allowed without permission.

414

415

416

417

418

419

420

421

422

423

424

425

426

427

428

429

430

431

36. Reyna, M. A., Leiserson, M. D. M. \& Raphael, B. J. Hierarchical HotNet: identifying hierarchies of altered subnetworks. Bioinformatics 34, i972-i980 (2018).

37. Schwartzentruber, J. et al. Genome-wide meta-analysis, fine-mapping and integrative prioritization implicate new Alzheimer's disease risk genes. Nat. Genet. 53, 392-402 (2021).

38. Bellenguez, C. et al. Large meta-analysis of genome-wide association studies expands knowledge of the genetic etiology of Alzheimer disease and highlights potential translational opportunities. medRxiv (2020) doi:10.1101/2020.10.01.20200659.

39. Lambert, J. C. et al. Meta-analysis of 74,046 individuals identifies 11 new susceptibility loci for Alzheimer's disease. Nat. Genet. 45, 1452-1458 (2013).

40. Du, Y. et al. LRRC25 inhibits type I IFN signaling by targeting ISG15-associated RIG-I for autophagic degradation. EMBO J. 37, 351-366 (2018).

41. Lee, M. et al. Acidic fibroblast growth factor (FGF) potentiates glial-mediated neurotoxicity by activating FGFR2 IIIb protein. J. Biol. Chem. 286, 41230-41245 (2011).

42. Pimenova, A. A. et al. Alzheimer's-associated PU.1 expression levels regulate microglial inflammatory response. Neurobiol. Dis. 148, 105217 (2021).

43. Zhang, Y. et al. Model-based analysis of ChIP-Seq (MACS). Genome Biol. 9, R137 (2008).

44. Marioni, R. E. et al. GWAS on family history of Alzheimer's disease. Transl. Psychiatry 8, 99 (2018). 
medRxiv preprint doi: https://doi.org/10.1101/2021.10.17.21264910; this version posted October 18, 2021. The copyright holder for this preprint (which was not certified by peer review) is the author/funder, who has granted medRxiv a license to display the preprint in perpetuity.

All rights reserved. No reuse allowed without permission.

Acknowledgments: We thank the patients and families who donated material for these studies. We thank the computational resources and staff expertise provided by the Scientific Computing group at the Icahn School of Medicine at Mount Sinai.

Funding: Supported by the National Institute on Aging, NIH grants R01-AG050986 (to P.R.), R01AG067025 (to P.R. and V.H.) and R01-AG065582 (to P.R. and V.H.). J.B. is partially supported by a NARSAD Young Investigator Grant 27209 from the Brain and Behavior Research Foundation (BBRF). P.D. is partially supported by a NARSAD Young Investigator Grant from the Brain and Behavior Research Foundation (BBRF).

Author contributions: J.F.F., V.H. and P.R. conceived of and initiated the project. J.F.F. and P.R. designed experimental strategies for omics profiling. A.W.C., B.K., D.B, C.P.K. and V.H. provided human brain tissue. J.F.F., S.R., S.P.K and Z.S. performed data generation. R.K., B.Z., J.B., G.E.H. and P.R. designed analytical strategies. R.K., J.B. and P.D. conducted initial bioinformatics, sample processing and quality control for the omics data. R.K. and G.E.H. developed the computational scheme and performed the downstream analysis. B.Z. performed the QTL analysis. J.B. performed the TF analysis. P.D. performed the Hi-C analysis. J.H., K.P.L. and T.R. provided additional QTL resources. J.F.F. and P.R. supervised overall data generation. G.E.H. and P.R. supervised overall data analysis. R.K., J.F.F., B.Z., J.B., G.E.H. and P.R. wrote the manuscript with input from all authors.

Competing interests: The authors declare no competing interests.

Data and materials availability: The genotypes, omics data and metadata are available via the AD Knowledge Portal (https://adknowledgeportal.org). The AD Knowledge Portal is a platform for accessing data, analyses, and tools generated by the Accelerating Medicines Partnership (AMP-AD) Target Discovery Program and other National Institute on Aging (NIA)-supported programs to enable open-science practices and accelerate translational learning. The data, analyses and tools are shared early in the research cycle without a publication embargo on secondary use. Data is available for general research use according to the following requirements for data access and data attribution (https://adknowledgeportal.org/DataAccess/Instructions). For access to content described in this manuscript see: http://doi.org/10.7303/syn26207321. Code used throughout this study (through Fig. $\mathrm{S} 16)$ is available upon reasonable request from the corresponding authors. 
medRxiv preprint doi: https://doi.org/10.1101/2021.10.17.21264910; this version posted October 18, 2021. The copyright holder for this preprint (which was not certified by peer review) is the author/funder, who has granted medRxiv a license to display the preprint in perpetuity.

a

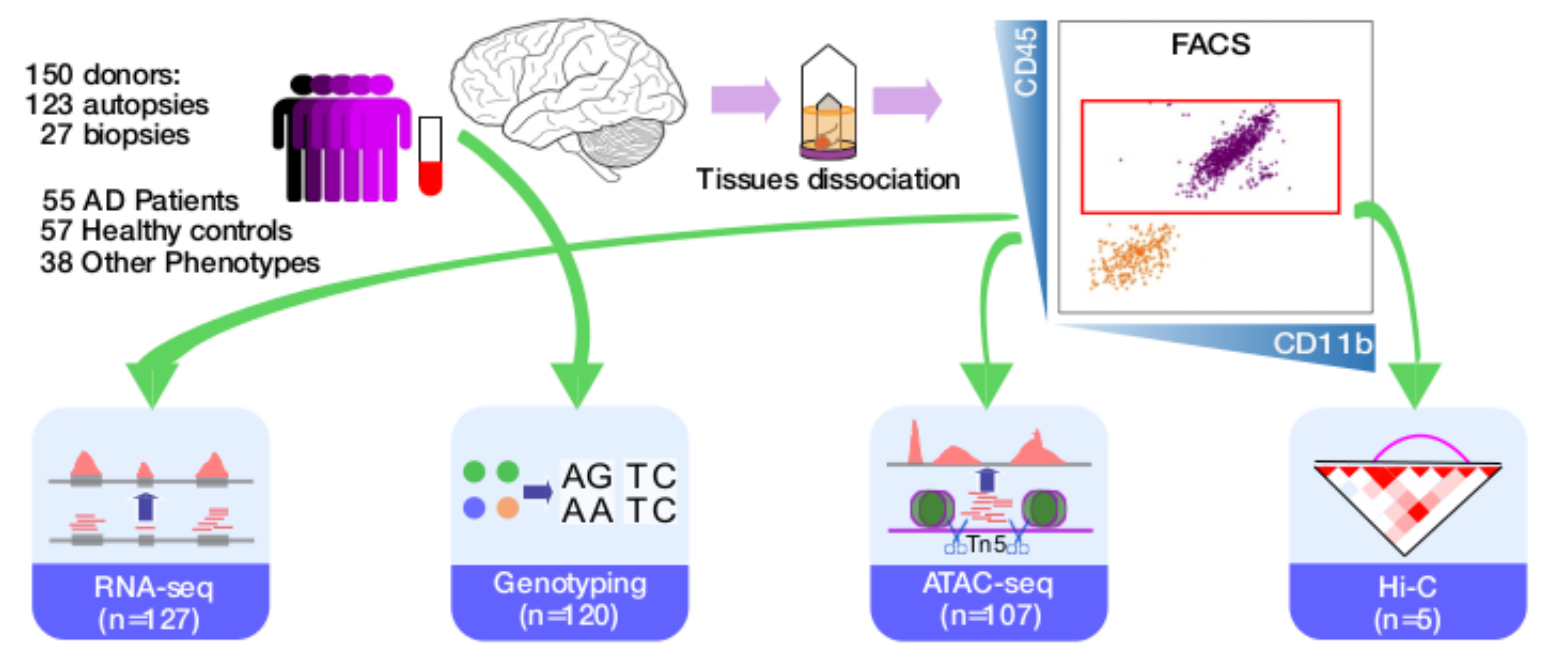

b

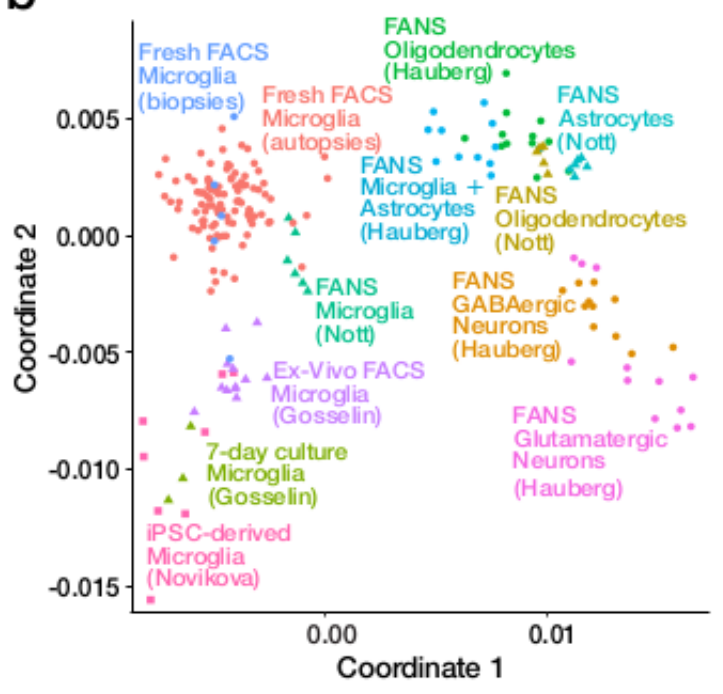

C

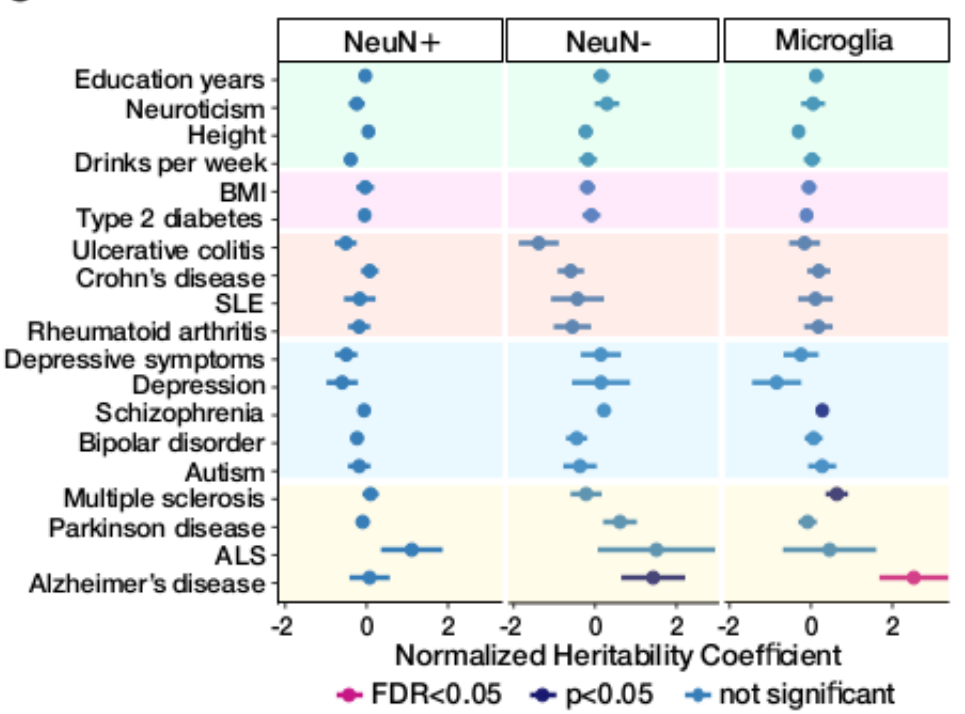

461 Fig. 1. Chromatin accessibility landscape in human microglia and AD predisposition. a)

462

463

464

465

466
Schematic outline of data generation. b) Comparison of human microglia ATAC-seq dataset to other brain open chromatin datasets (Table S2) utilizing jointly called OCRs in multidimensional scaling space. c) Enrichment of trait-associated genetic variants in neuronal (NeuN+), non-neuronal (NeuN-), microglia and microglia-specific OCRs. Coefficients from LD score regression are normalized by the per-SNP heritability (h2 / total SNPs per GWAS). Horizontal bars indicate standard error. 
467

468

469

470

471

472

473

474

475

476

477

478

479

480

481

482

483

484

485

486

487

488

489

490

491

492

493

494

495 a

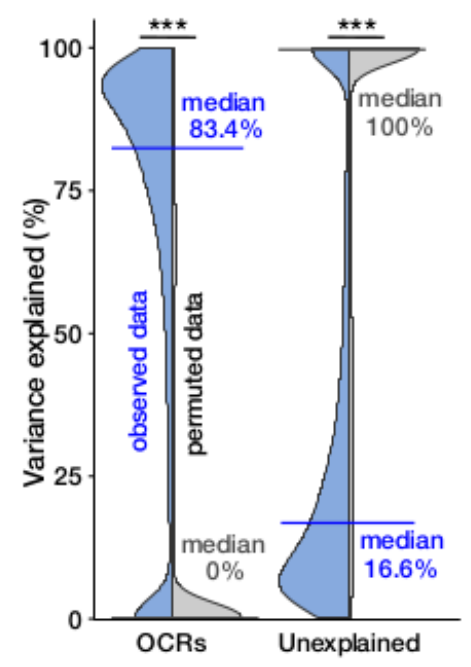

C

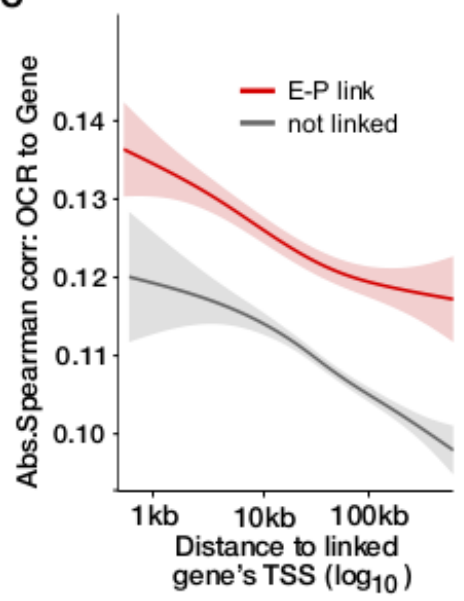

b
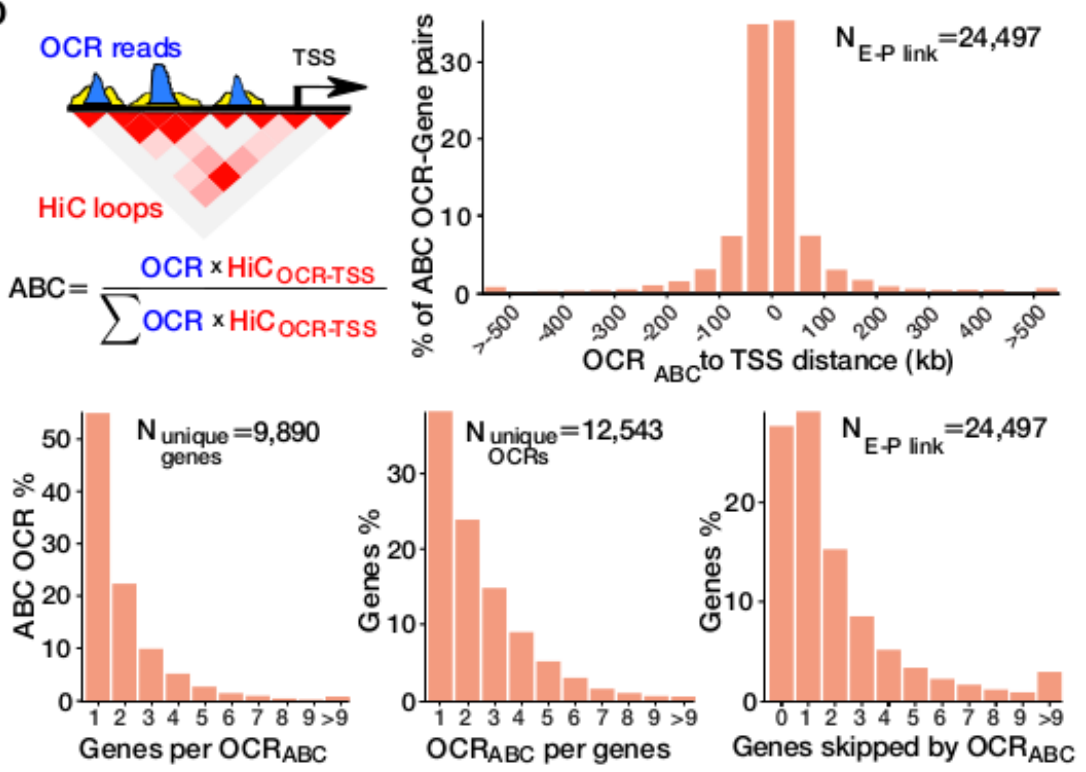

d

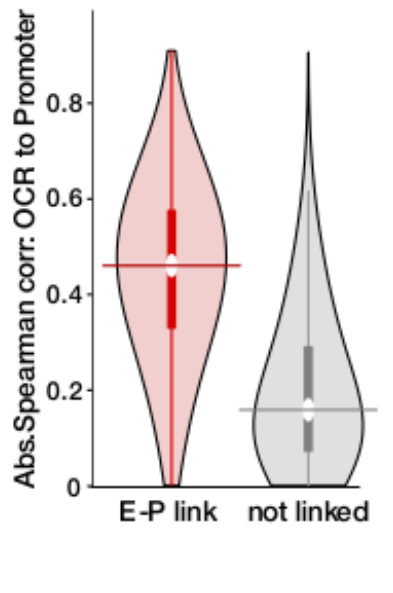

e

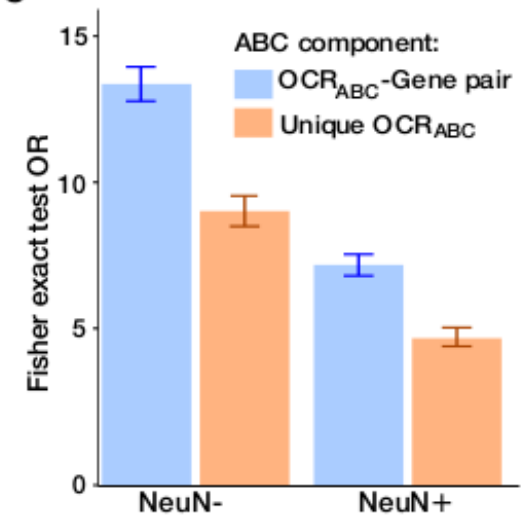

f

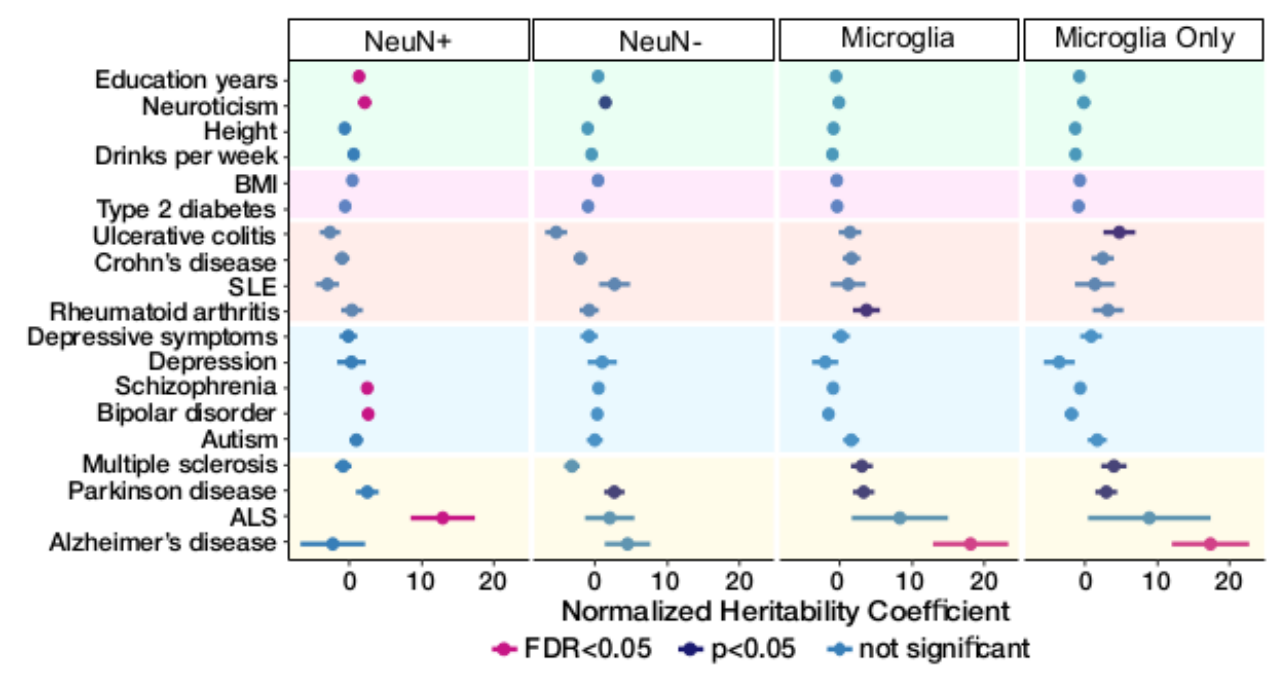

Fig. 2. Transcriptional regulation by open chromatin regions. a) Fraction of transcriptional variation for each gene explained by accessible chromatin for observed data (blue) and permuted data 
medRxiv preprint doi: https://doi.org/10.1101/2021.10.17.21264910; this version posted October 18, 2021. The copyright holder for this preprint (which was not certified by peer review) is the author/funder, who has granted medRxiv a license to display the preprint in perpetuity.

All rights reserved. No reuse allowed without permission.

496 (grey). b) Distribution of distance from TSS for E-P interactions (top right); histograms of the number 497 of $\mathrm{OCR}_{\mathrm{ABC}}$ per gene (bottom left), the number of genes per OCR $\mathrm{ABC}_{\mathrm{AC}}$ (bottom middle) and the number of 498 skipped genes between the $\mathrm{OCR}_{\mathrm{ABC}}$ and the linked gene (bottom right). c) $\mathrm{OCR}_{\mathrm{ABC}}$ involved in E-P

499 interactions have stronger correlation with the expression of the corresponding gene compared to non

500 E-P pairs. d) $\mathrm{OCR}_{\mathrm{ABC}}$ involved in E-P interactions have stronger correlation with the OCR at the linked

501 promoter compared to OCRs not in an E-P link. Horizontal lines indicate the median, and thick vertical

502 lines indicate 25\%-75\% quantiles. e) Enrichment of microglia E-P interactions with non-neuronal

503 (NeuN-) and neuronal (NeuN+) E-P interactions. Colored bars indicate the odds ratio and error bars

504 represent 95\% confidence intervals. f) Enrichment of trait-associated genetic variants in neuronal

505 (NeuN+), non-neuronal (NeuN-), microglia and microglia-specific E-P interactions. Coefficients from

506 LD score regression are normalized by the per-SNP heritability (h2 / total SNPs per GWAS).

507 Horizontal bars indicate standard error. 
a

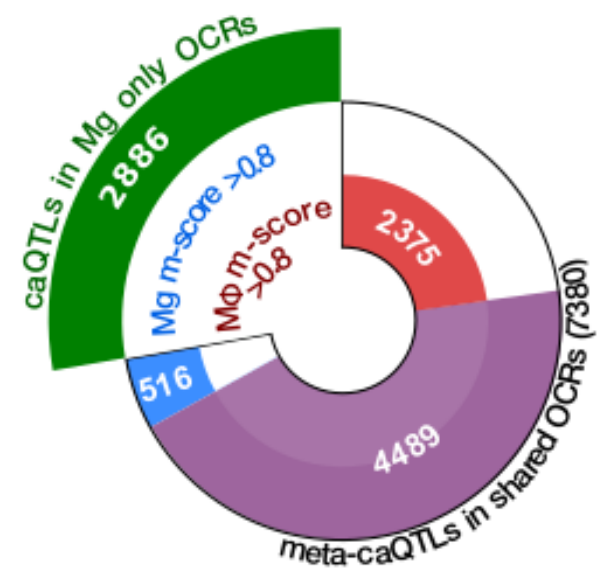

C

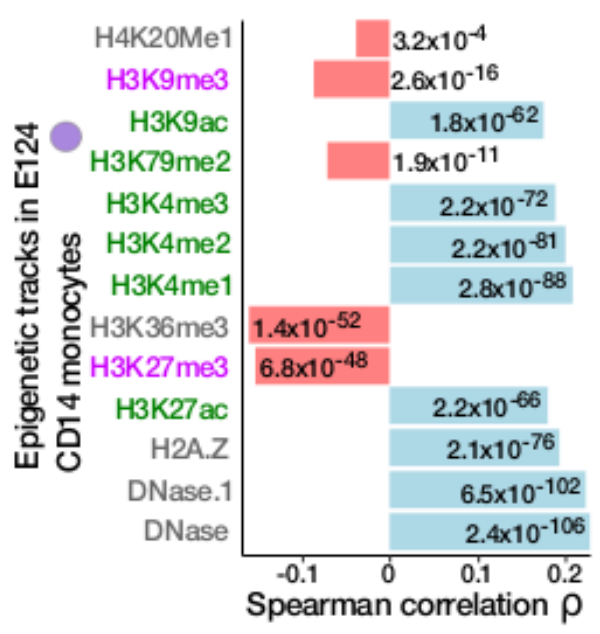

b

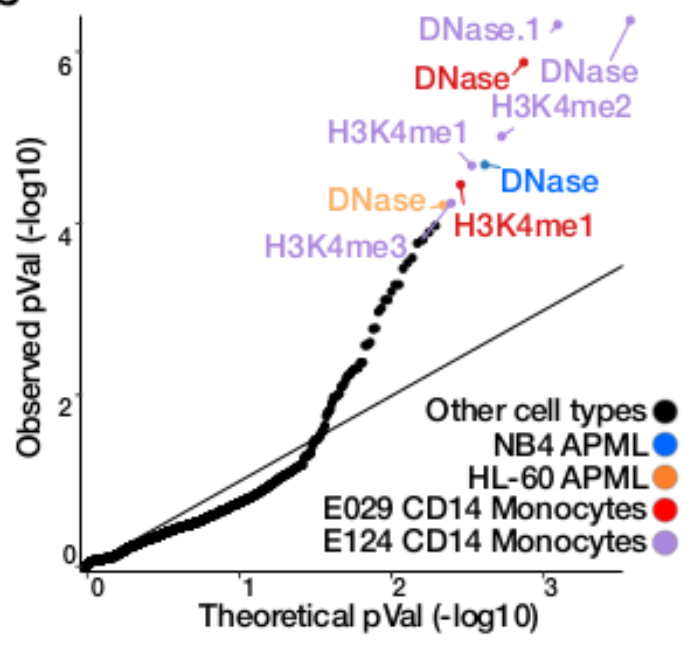

e

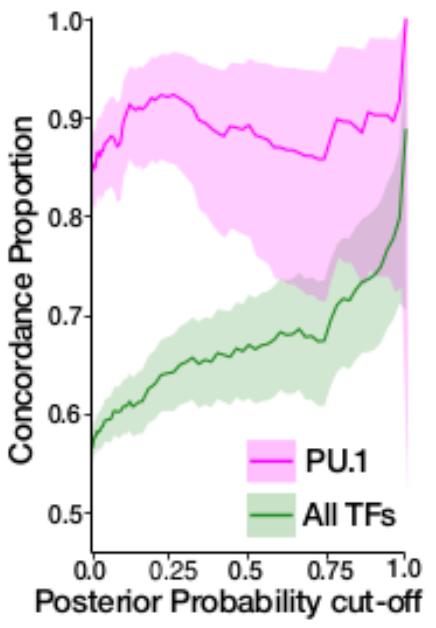

f

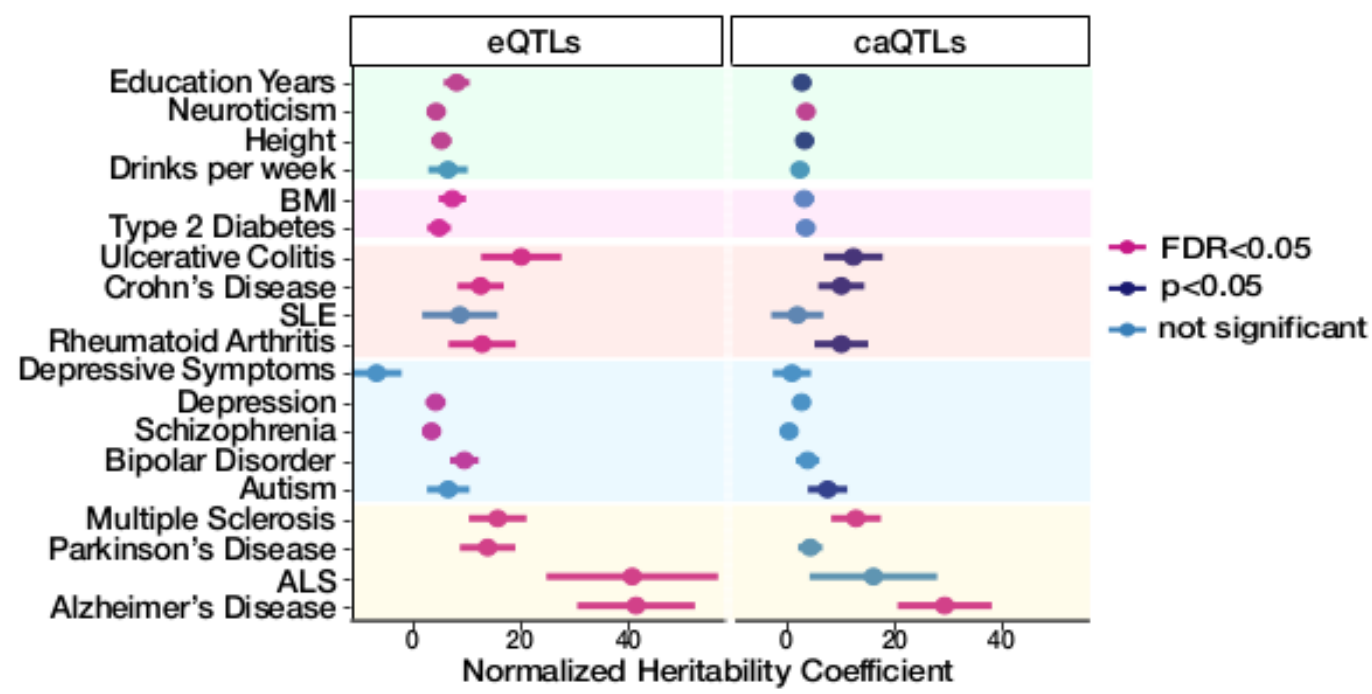

Fig. 3. Genetic regulation of chromatin accessibility in human microglia. a) Count of OCRs with caQTL signals in microglia $(\mathrm{Mg})$ and macrophages $(\mathrm{M} \varphi)$ shown by cell type specificity based on 
medRxiv preprint doi: https://doi.org/10.1101/2021.10.17.21264910; this version posted October 18, 2021. The copyright holder for this preprint (which was not certified by peer review) is the author/funder, who has granted medRxiv a license to display the preprint in perpetuity.

All rights reserved. No reuse allowed without permission.

554 Bayesian meta-analysis. Analysis of microglia-only OCRs gives caQTLs specific to microglia (green), and analysis of shared OCRs gives both shared and cell type specific caQTLs. b) QQ plot of p-values reflecting the concordance between DeepSEA predictions and caQTL regression coefficient.

557 Significant assays from myeloid lineages are indicated by colors. c) Spearman correlation between 558 caSNPs' effect size estimated by caQTL analysis and by DeepSEA predicted effect on epigenetic

559 assays for promoters/enhancers (green) and repressors (purple). P-values for each test are indicated. d)

560 Concordance between caSNPs' allelic effects on chromatin accessibility and the predicted change in

561 motif binding ability for PU.1 compared to all 53 TFs (including PU.1), whose binding sites were significantly disrupted by caSNPs. Concordance is shown as a function of posterior probability from fine-mapping, and shaded regions indicate 95\% confidence intervals. e) Enrichment for fine-mapped caSNPs within OCRABC also being fine-mapped eSNPs for the target genes compared to those in OCRs not involved in E-P interactions. Enrichments are shown over a range of posterior probability cutoffs applied to both caSNPs and eSNPs. Shading indicates 95\% confidence interval. f) Enrichment of trait-associated genetic variants in 95\% credible set of microglia meta-eSNPs and meta-caSNPs. Coefficients from LD score regression are normalized by the per-SNP heritability ( $\mathrm{h} 2$ / total SNPs per GWAS). Horizontal bars indicate standard error. 

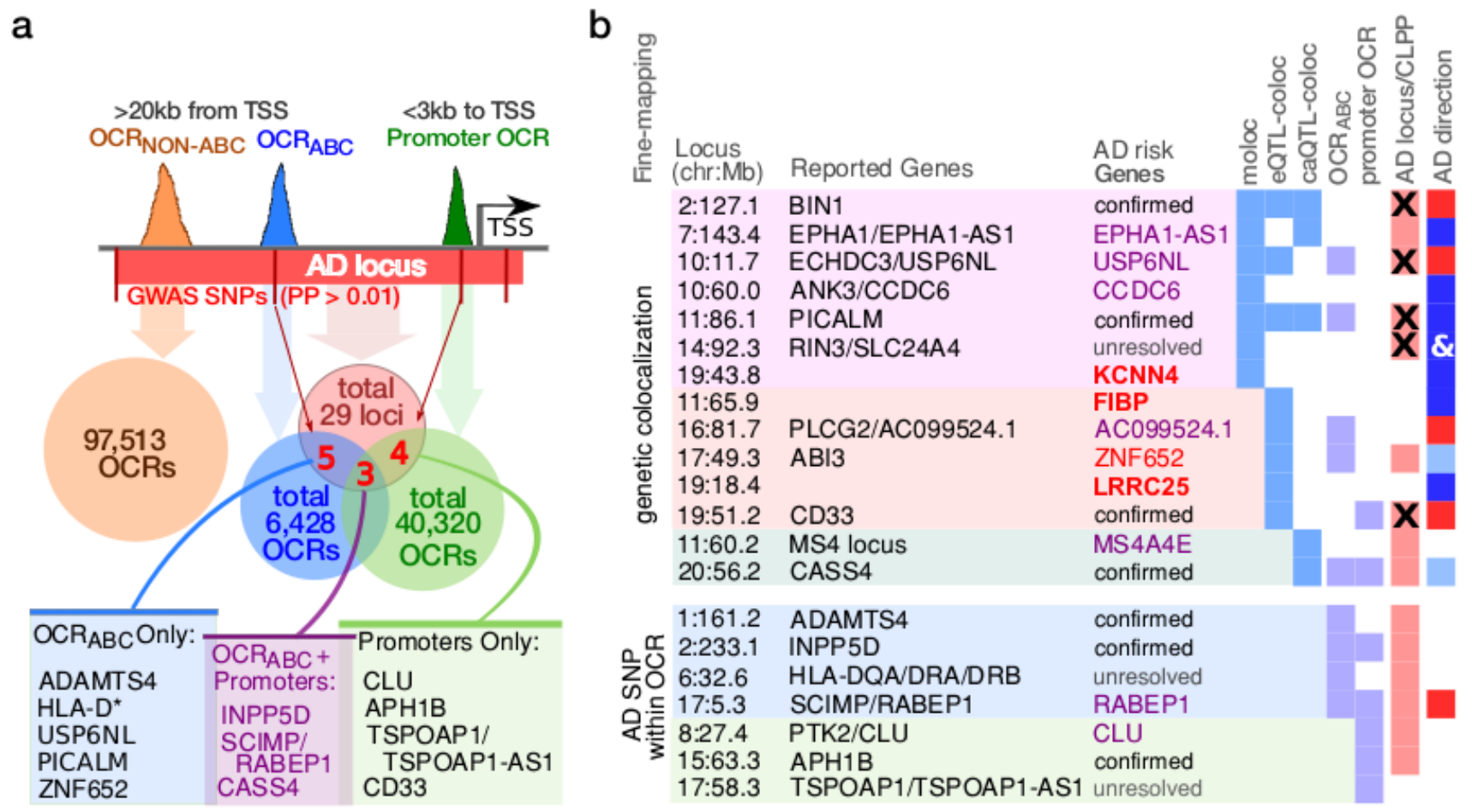

C

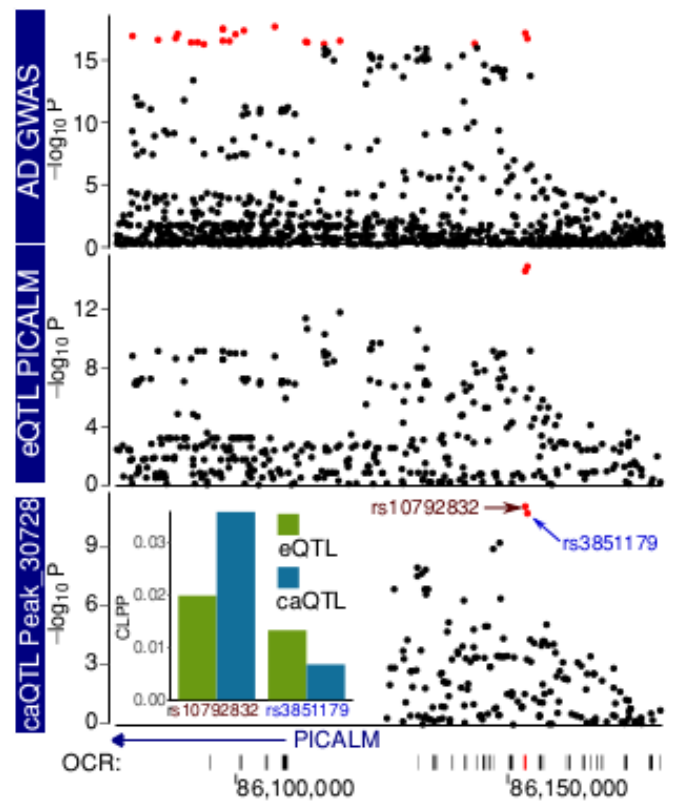

d

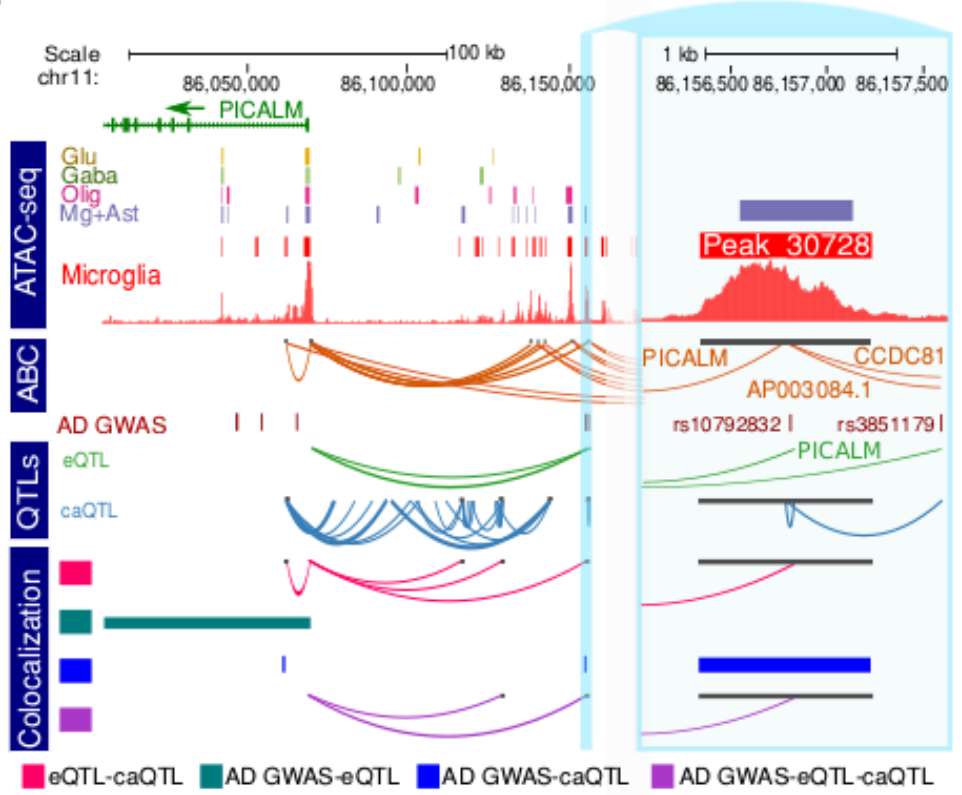

570 Fig. 4. Integration of AD etiologic landscape with genetic regulation of transcriptional andomatin

571 accessibility in microglia. a) Overlap of 316 fine-mapped SNPs from 29 AD GWAS loci ${ }^{12}$ with

572 OCRABC (blue) and promoters (green); b) Fine-mapping to define candidate AD genes based on: a)

573 joint colocalization for eQTL, caQTL and GWAS signal ('moloc'); colocalization for (b) eQTL and

574 GWAS ('eQTL-coloc'); and (c) caQTL and GWAS ('caQTL-coloc') signal; fine-mapped AD variants

$575(\mathrm{PP}>0.01)$ within $(\mathrm{d}) \mathrm{OCR}_{\mathrm{ABC}}$ and (e) promoter OCR. 'AD GWAS' indicates regions identified by

576 Jansen et al. ${ }^{12}$, and ' $\mathrm{x}$ ' indicates significant joint fine-mapping with gene expression or chromatin

577 accessibility. 'AD direction' is the linked gene's expression in relation to the AD risk alleles 
578 (red=higher; blue=lower, ' $\&$ ' indicates consistency for multiple genes in the region). Color schema for 'Linked Genes': genes are unambiguously fine-mapped and previously implicated in AD (purple); not

580 previously fine-mapped as AD risk genes (red). Novel putative AD risk genes outside previously

581 reported AD loci are shown in bold. c) Local plot showing results from AD GWAS ${ }^{12}$, eQTL analysis of

582 PICALM, and caQTL analysis of peak_30728. Red points indicate genetic variants in the $95 \%$ credible

583 set from statistical fine-mapping of each trait. Inset shows colocalization posterior probabilities (CLPP)

584 for the top variants in the credible set for gene expression and chromatin accessibility. d) Visualization

585 of the PICALM locus showing: open chromatin regions from 4 cell populations ${ }^{5}$ and microglia from

586 this study; E-P interactions (ABC); fine-mapped (PP>0.05) SNPs from AD GWAS ${ }^{12,39,44}$; genetic

587 regulation from eQTLs and caQTL form thus study; and colocalization analysis between pairs of traits

588 (i.e. AD GWAS, gene expression chromatin accessibility) using 'coloc' and all three traits using

589 'moloc' methods. 
590

591 a

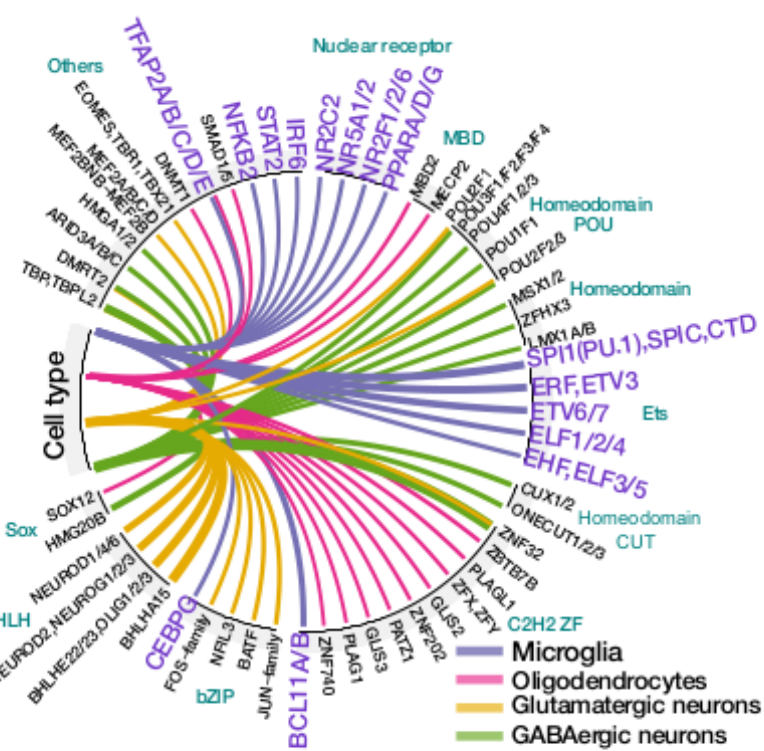

b

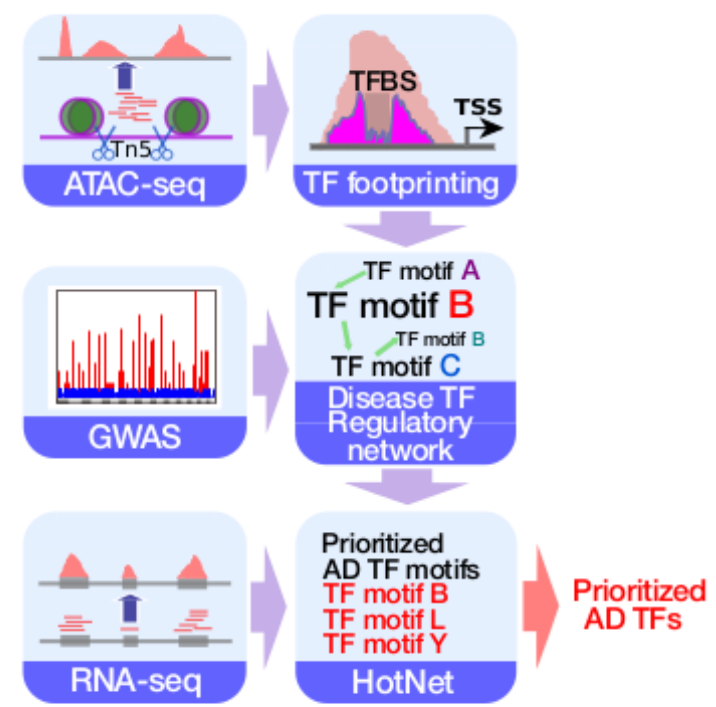

C

\section{d}

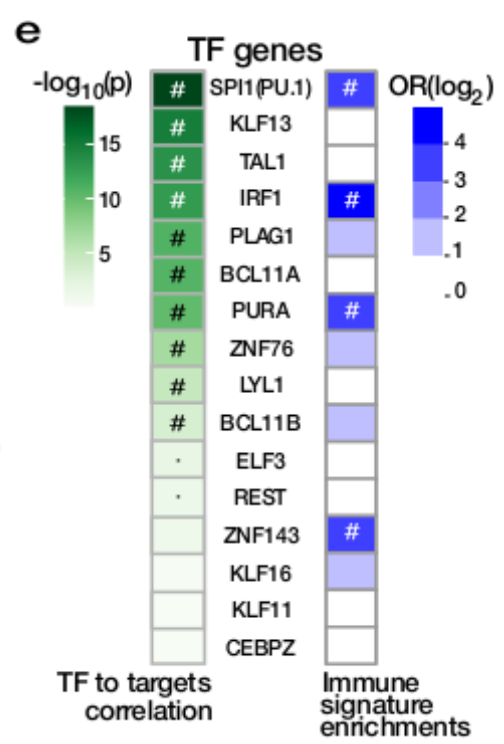

SPI1 (PU.1-coding)expression:

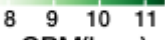
$\mathrm{CPM}\left(\log _{2}\right)$

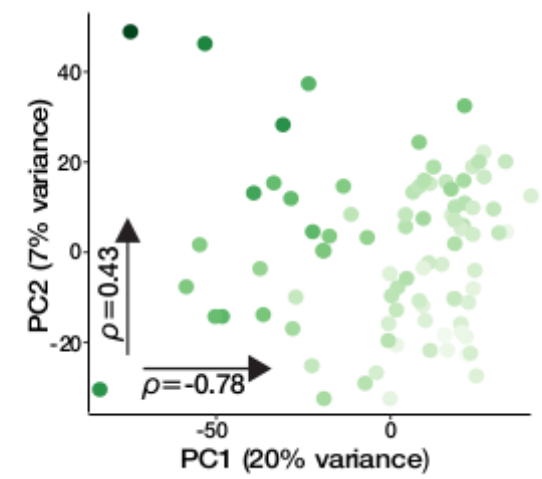

Fig. 5. Transcription factor binding landscape in microglia integrating AD genetics. a) Top cellspecific TF binding events detected by TF footprinting in the microglia and three other major brain cell lineages ${ }^{5}$. Line thickness indicates the fold enrichment in the highlighted cell types compared to the mean number of bound TFs in other cell types (all $\mathrm{BH}<0.05$, one-sided binomial test); b) Schema for AD TF prioritization analysis; c) Aggregated footprint profile of PU.1 motif within the jointly called OCRs in the four cell populations; d) Principal component analysis of expression for predicted PU.1 targets genes for $n=127$ samples colored by expression of PU.1-encoding SPI1 gene. Spearman correlation $(\rho)$ with each principal component; e) Prioritization of TFs from AD TF regulatory networks based on correlation with respective downstream target genes (shaded in green by $p$-value, $' \#$ ' $=\mathrm{BH}<0.05, ' \cdot=\mathrm{p}$-value $<0.05$ ). Right column: Enrichment analyses of the TF downstream target genes for immune-related gene signatures. The values represent odds ratio enrichment for immunerelated signatures among all functional signatures. Significant enrichment $(\mathrm{BH}<0.05)$ is indicated by “\#”. 
medRxiv preprint doi: https://doi.org/10.1101/2021.10.17.21264910; this version posted October 18, 2021. The copyright holder for this preprint

(which was not certified by peer review) is the author/funder, who has granted medRxiv a license to display the preprint in perpetuity.

All rights reserved. No reuse allowed without permission.

620 Supplementary Materials (provided separately)

621 Materials and Methods

622 Supplementary Text

623 Figures S1-S24

624 Tables S1-S7

625 References (45-78) 